\title{
A UTILIZAÇÃO DE OBJETOS EDUCACIONAIS COMO RECURSO DIDÁTICO PARA O ENSINO DE QUÍMICA NAS SÉRIES FINAIS DO ENSINO FUNDAMENTAL ${ }^{1}$
}

\begin{abstract}
Eriklys Darlan Gomes Bezerra, graduando em química UACEN/CFP/UFCG, eriklysdarlan@gmail.com
\end{abstract}

Thalyta Pessoa Freire, graduanda em química UACEN/CFP/UFCG, thalytafreire1@gmail.com

Edilson Leite da Silva, professor UACEN/CFP/UFCG, souedilsonleite@gmail.com

\section{RESUMO}

Muitos são os fatores que tornam o ensino de química difícil, desde a falta de materiais de laboratório até os conceitos abstratos que ela trabalha, e assim torna sua aprendizagem complicada, pois nela necessita-se a visualização de fenômenos que ocorrem em nível atômico. Como resultado do desenvolvimento das TIC's, surgiram os Objetos Virtuais de Aprendizagem (OVA), que permitem o desenvolvimento de habilidades e estimulando a comunicação. Com a crescente preocupação pelo desenvolvimento de metodologias que facilitem o processo de ensino-aprendizagem, estimulem os discentes a buscarem $o$ conhecimento e levem a um ensino efetivo, chegou-se ao desenvolvimento desta pesquisa que avaliou a eficácia da utilização dos Objetos Virtuais de Aprendizagem no ensino de química nas séries finais do ensino fundamental. $\mathrm{O}$ caminho percorrido neste trabalho consistiu em realizar uma pesquisa bibliográfica sobre o tema estudado, seguido da aplicação de metodologias de ensino apoiadas nos OVA em duas turmas do $9^{\circ}$ ano da Escola Estadual Professor Adalberto de Sousa Oliveira.

PALAVRAS-CHAVE: Tecnologias da Informação e Comunicação; Objetos Virtuais de Aprendizagem; Processo de ensino aprendizagem.

THE USE OF EDUCATIONAL OBJECTS AS A RESOURCE FOR TEACHING CHEMISTRY IN THE FINAL GRADES OF SECONDARY SCHOOL

\author{
ABSTRACT
}

\footnotetext{
${ }^{1} \mathrm{O}$ presente trabalho não contou com apoio financeiro de nenhuma natureza para sua realização.
} 
There are many aspects that make Chemistry teaching difficult, from the lack of laboratory materials to the abstract concepts it works on, and thus makes its learning complicated because it requires the visualization of phenomena that occur at the atomic level. As a result of the development of the TICs, Virtual Learning Objects (OVA) have emerged, which allows the development of skills and encourages communication. With the growing concern for the development of methodologies that facilitate the teaching-learning process, stimulate the students in the search for knowledge and lead to an effective teaching, led the development of this research which evaluated the effectiveness of the use of Virtual Learning Objects in teaching Chemistry in the final grades of Secondary School. The path taken in this work consisted in carrying out a bibliographical research on the studied subject, followed by the application of teaching methodologies supported in the OVA in two classes of the 9th grade of the Escola Estadual Professor Adalberto de Sousa Oliveira.

KEYWORDS: Information and Communication Technologies; Virtual Learning Objects; Teaching-learning process.

\section{LA UTILIZACIÓN DE OBJETOS EDUCATIVOS COMO RECURSOS DIDÁCTICOS PARA LA ENSEÑANZA DE QUÍMICA EM LAS SERIES FINALES DE LA ENSEÑANZA FUNDAMENTAL \\ RESUMEN}

Muchos son los factores que hacen que la enseñanza de química difícil, desde la falta de materiales de laboratório hasta los conceptos abstractos que ella trabaja, y así hace su aprendizaje complicado, pues en ella se necesita la visualización de fenómenos que ocurren a nivel atómico. Como resultado del desarrollo de las TIC's, surgieron los Objetivos virtuales de Aprendizaje (OVA), que permite el desarrollo de habilidades y estimulando la comunicación. Con la creciente preocupación por el desarrollo de metodologías que facilite el proceso de enseñanza-aprendizaje, estimule a los alumnos a buscar por el conocimiento y llevar a una enseñanza efectiva, indujo el desarrollo de esta investigación que evaluó la eficacia de la utilización de los, Objetos Virtuales de Aprendizaje en la enseñanza de química en las series finales en la enseñanza fundamental. El camino recorrido en este trabajo consistió en realizar una investigación bibliográfica sobre el tema estudiado, seguido de la aplicación de metodologías de enseñanza apoyadas en los OVA en dos clases del $9^{\circ}$ año de la Escuela Estadual Profesor Adalberto de Sousa Oliveira.

PALABRAS-CLAVE: Tecnologías de la información y comunicación; Objetos Virtuales de Aprendizaje; Proceso de enseñanza aprendizaje.

\section{INTRODUÇÃO}

O ensino de química enfrenta diversas dificuldades, pois os professores, geralmente, não encontram recursos a sua disposição para trabalhar de forma que sejam capazes de 
capturar a atenção dos alunos e estimule-os a aprender. A Química sendo uma ciência que possui conceitos abstratos torna o processo complicado, tendo em vista a exigência a visualização de fenômenos os quais são, muitas vezes, de ordem microscópica.

O desenvolvimento dos computadores e das Tecnologias da Informação e Comunicação (TIC's) abriu um novo leque de possibilidades para a educação, tornando o processo de ensino-aprendizagem mais dinâmico e interativo. Nesse contexto surge os OVAs, ferramentas capazes de contornar as dificuldades enfrentadas pelos professores de química, pois estes são capazes de melhorar a visualização de fenômenos macroscópicos e microscópicos, contribuindo com a interação, estimulando a curiosidade e, assim, produzir um ensino contextualizado, no qual crie vínculo de teoria e prática.

É notória a existência de uma preocupação crescente com o desenvolvimento de metodologias que facilitem o processo da educação, melhorando sua qualidade e tornando o ensino mais atraente para estimular os discentes e diminuir as suas reclamações em relação às dificuldades das disciplinas, a chatice e a falta de estímulo, principalmente quando se trata de Química. A partir deste e de outros fatos procurou-se desenvolver um ensino no qual rompesse esses paradigmas através da busca de metodologias de ensino, apoiadas na utilização de OVA, e pudesse produzir um ensino efetivo, capaz de mudar a realidade vivida pela educação nos dias atuais.

Como já se compreende a Química é a ciência na qual estuda a matéria, suas transformações, propriedades e estrutura, possuindo importância considerável. Sendo assim, é possível a partir da utilização de objetos de aprendizagem tornar o ensino desta mais atraente e, além disso, tornar este mais compreensível? Através deste questionamento surge a necessidade de desenvolvimento deste trabalho, cujo objetivo geral é avaliar a eficácia da utilização dos objetos virtuais de aprendizagem no ensino de química nas séries finais do ensino fundamental, pela construção de metodologias, baseadas na utilização destes, oferecendo aos discentes a aquisição de conhecimentos mais sólidos.

\section{REFERENCIAL TEÓRICO}

O ensino de química encontra grandes dificuldades, principalmente pelo desinteresse dos jovens por essa área. Santos e Porto (2013), ao traçar uma perspectiva histórica dos 
desafios enfrentados pela área de Ensino de Química, mostra que o desinteresse dos jovens pela química não é atual e sim histórico. Em consequência disso, surgiram grandes investimentos em projetos educacionais nos quais desenvolveram materiais didáticos para a educação básica em ciências.

A química é uma ciência complexa de nível relativamente elevado, dificultando a transmissão do seu conhecimento, além da assimilação do mesmo. Para contornar tal problema Soares, Silveira e Nunes (2013) acreditam na experimentação como uma possível solução, mas, ao mesmo tempo, afirmam a dificuldade encontrada em um ensino baseado na mesma, pois o custo de instalação e manutenção de um laboratório pode ser elevado, assim ocorre indução para uma aprendizagem menos efetiva, visto que os professores não dispõem de muitas alternativas para tornar o ensino de química efetivo, atraente, que aproxime a teoria da prática.

Uma alternativa viável para contornar essas dificuldades no ensino de química é a utilização de simuladores e outros softwares computacionais que permitam a criação de conhecimentos práticos e lúdicos, essenciais ao ensino de química. A educação deve desvincular-se de métodos tradicionalistas de ensino no qual apenas a lousa e o giz ou caneta de quadro branco é/são utilizados, nos tempos atuais onde o domínio da informática é grande e as possibilidades são inúmeras, principalmente com a presença da internet, softwares e aplicativos computacionais (SOARES et al., 2013).

Unir o desenvolvimento tecnológico a educação não é algo novo, segundo Leite e Ribeiro (2012), desde a década de 1970, quando teve início a instalação dos primeiros computadores nas escolas, iniciou-se a discussão sobre as possibilidades de uso na educação. Após o aparecimento dos computadores surgiram os seus periféricos (Scanners, impressoras, etc.), esse conjunto passou a ser identificado como tecnologia da informação (TI), com o passar do tempo surgiu a World Wide Web, da sigla em inglês WWW, e outras tecnologias aliadas que permite comunicação a distância (e-mail, ferramentas de busca, etc.) surgindo assim uma nova denominação para essas tecnologias, que permite "criar, captura, interpretar, armazenar, receber e transmitir informações" (LEITE; RIBEIRO, 2012, p. 175): TIC's, acrônimo para tecnologias da informação e comunicação.

Leite e Ribeiro (2012) acredita ser fundamental a inclusão das TIC's no ensino, pois a sociedade na qual estamos imersos necessita, cada vez mais, de pessoas que possuam um 
domínio razoável das novas tecnologias e nada melhor que a escolas para produzir esse domínio e incluir os educandos nesse novo mundo.

Nesse contexto, o surgimento de computadores cada vez mais poderosos proporciona o aparecimento de novas ferramentas educacionais apoiando o ensino, a exemplo, podemos citar os Objetos Virtuais de Aprendizagem, cuja principal característica é sua reutilização para os mais diferentes processos de aquisição de conhecimento. Essas ferramentas promovem o desenvolvimento de habilidades e estimula a comunicação, apresentando uma ideia de elaboração conjunta, no qual todos produzem quase ao mesmo tempo, onde nenhum dos objetos produzidos seja particular desta ou daquela pessoa (SCHWARZELMÜLLER; ORNELLAS, 2012).

O computador é uma ferramenta eficiente que melhora o processo de ensino aprendizagem, pois, para Barão (2007), este promove motivação e aumenta a interação, elevando a curiosidade. Outro ponto é a possibilidade da visualização de fenômenos químicos que, sem a ajuda de tais ferramentas, não podiam. Os OVA disponibilizados nos espaços virtuais, graças aos computadores, e a rede mundial que os conecta, promove a melhor assimilação dos conteúdos que antes eram abstratos e sem contextualização.

Ensinar em espaços virtuais realmente permite ao aluno fazer correlações mais acertadas com o conteúdo visto em sala de aula, ele interage, visualiza fenômenos que antes eram impossíveis, pois na química não se dispõe de materiais de visualização como em outras disciplinas. (BARÃO, 2007, p. 15)

O desenvolvimento das TIC's e a sua consequente inserção na educação, os computadores e outros recursos tecnológicos, além dos conteúdos disponibilizados na internet, passaram a serem considerados essenciais no auxílio pedagógico, nessa ocasião os OVA dão oportunidades no apoio da aprendizagem, cujo intermédio corre pelo computador, tornando o ensino coerente. Seja na educação presencial ou à distância eles surgem como uma tecnologia que pode produzir benefícios a discentes e docentes (GALAFASSI; GLUZ; GALAFASSI, 2013).

Para Spinelli (2007) atividades que favorecem o desenvolvimento da criatividade pelos educandos não é privilégio daqueles que utilizam da tecnologia, entretanto, o seu uso pode aumentar as possibilidades para o crescimento da criatividade.

Os OVA é uma tecnologia recente, não havendo uma definição clara, mas percebe-se sempre a presença da ideia de reutilização. Para ser considerado um OVA é necessário que 
este atenda a uma série de características técnicas, além de possuir uma aplicação educacional, logo este pode ser analisado em dois pontos de vista: no pedagógico, relaciona a criação do objeto com características que contribua no trabalho do professor e dos alunos, e no técnico, influenciado pela padronização que torna possível sua utilização em diversos contextos (GALAFASSI; GLUZ; GALAFASSI, 2013).

Spinelle (2007, p.7) define, em linhas gerais OVA é "um recurso digital reutilizável que auxilie na aprendizagem de algum conceito", encorajando o progresso da imaginação e da criatividade. Assim, este pode ser utilizado desde o desenvolvimento de um único conteúdo até o de uma teoria, além disso, pode construir um caminho instrutivo, englobando várias atividades, abordar situações particulares do conteúdo, ou, simplesmente, ser o caminho adotado para certo trabalho.

A seleção de um OVA necessita de uma análise criteriosa, já que, muitas vezes o próprio criador não possui compreensão da teoria da aprendizagem que está ligado a ele. Durante sua vida escolar o aluno convive com diferentes professores e componentes curriculares cada qual com um enfoque teórico (BULEGON; MUSSOI, 2014).

Durante a aula é que ocorre a solidificação das estratégias antes planejadas, embora os conteúdos possam ser trabalhados da maneira mais conveniente para atingir os objetivos, ou seja, deve-se ter uma flexibilidade na execução da aula que antes foi preparada a fim de sanar todos e quaisquer questionamentos que venham a surgir. Sendo assim o planejamento está diretamente ligado ao processo educacional, por consequência a utilização de um OVA possui uma intenção pedagógica, não simplesmente deve ser utilizado para atrair a atenção do aluno, mas que possa auxiliar o professor no processo de ensino e ao aluno no processo de aprendizagem (MENEZES; BRAGA, 2014).

Vejamos o pensamento de Menezes e Braga (2014, p. 59): “A análise criteriosa do contexto pedagógico e dos OA disponíveis é que possibilitará um bom trabalho. Não há uma receita pronta que estabeleça: o OA X está para o contexto X, invariavelmente".

A exemplo do exposto anteriormente, Lazzaris et al (2014) tendo a finalidade de investigar o quão se torna efetiva a compreensão de conceitos abstratos utilizando um simulador virtual sobre pilhas galvânicas, ele procedeu com a aplicação de um OVA de seguinte forma: Inicialmente apresentou conceitos relacionados às pilhas galvânicas, ou seja, deu conceitos sobre oxirredução, balanceamento pelo método da oxidação redução, além de 
uma explanação sobre a pilha de Daniel e por último a resolução de exercícios. O passo seguinte adotado por ele foi a utilização do simulador Chemical Education Research Group, ilustrando como ocorrem os processos de oxirredução. Os resultados obtidos por ele mostram a efetividade de sua metodologia para o seu contexto, já que cada contexto educacional requer uma metodologia que se adeque.

\section{METODOLOGIA}

Esta pesquisa foi desenvolvida na E. E. E. F. M. Professor Adalberto de Sousa Oliveira, localizada na cidade de Cachoeira dos Índios no estado da Paraíba, com a participação de 40 alunos do $9^{\circ}$ ano do ensino fundamental distribuídos em duas turmas (A e B). A aplicação dos OVA ocorreu apenas na turma A, sendo que a turma B serviu de padrão para fins de comparação do desempenho dos alunos.

Em um primeiro momento foi discutido o conteúdo propriedades da matéria através de uma aula expositiva e dialogada, com problematização sobre as formas como podemos identificar os materiais em ambas as turmas. Em seguida, exibiu-se para a turma A o vídeo como congelar a água em um minuto, disponível no link $<$ https://www.youtube.com/watch?v=7d4GhLCHQ20 $>$. Ainda na mesma turma utilizou-se o do simulador Sais e Solubilidade disponibilizado na internet pelo projeto PhET Simulações Interativas, da Universidade de Colorado Boulder, disponível no link <https://phet.colorado.edu/ptBR/simulation/legacy/soluble-salts $>$, sendo que este foi exibido com auxílio de Datashow.

Em outro momento discutiu-se o tema densidade, em ambas as turmas, onde foi proposto o seguinte problema: como podemos separar os feijões sadios dos estragados? $\mathrm{Na}$ turma A teve a visualização do fenômeno densidade com a exibição de um simulador, disponibilizado também pelo projeto PhET no link <https://phet.colorado.edu/pt_BR/simulation/legacy/density>.

Para reforçar os conteúdos ministrados, na turma A, exibiu-se os vídeos kitesurf densidade e solubilidade I, disponíveis nos links, respectivamente: <https://www.youtube.com/watch?v=awkXVS8eYbs\&feature=youtu.be > 
<http://web.ccead.pucrio.br/condigital/video/ai\%20tem\%20quimica/solubilidade/solubilidade 1/video\%20para\%20web/video.html $>$.

Por último, foi desenvolvida uma atividade interativa no laboratório de informática da escola com os simuladores: “A calda tem química?" e "sua joia é verdadeira?", disponibilizados pelo LabVirt da USP.

Considera-se esta pesquisa como aplicada, de cunho explicativa, tendo em vista que a mesma procurou analisar os fatos estudados relacionando a possíveis fatores que viessem a interferir na aprendizagem significativa, sendo ainda um estudo de campo, pois buscou-se os resultados diretamente com a população estudada e, além disso, possui caráter quantitativo qualitativo.

Os dados pertinentes às análises quantitativas foram coletados a partir da aplicação de um questionário na forma exercício de verificação da aprendizagem, onde este foi elaborado no sentido de problematizar o conhecimento adquirido pelo aluno durante o desenvolvimento do projeto. A avaliação qualitativa ocorreu cotidianamente durante o desenvolvimento do projeto, no qual se observou pontos como: comportamento perante os temas apresentados, interação durante as aulas, habilidades cognitivas adquiridas ao levantar algum questionamento em sala, entre outros.

\section{RESULTADOS E DISCUSSÕES}

Os resultados foram obtidos a partir da aplicação de um questionário na forma de exercício de verificação da aprendizagem compreendido por 04 questões discursivas, cujo objetivo era verificar a eficácia da utilização dos objetos virtuais de aprendizagem no ensino de Química nas séries finais do Ensino Fundamental.

No primeiro quesito foi proposta a determinação da densidade de um bloco metálico, no qual a unidade deveria ser mensurada em $\mathrm{g} / \mathrm{cm}^{3}$. No problema disponibilizava-se a massa, em $\mathrm{kg}$, e o volume, em $\mathrm{cm}^{3}$, assim sendo, esperava-se que estes convertessem a referida massa de $\mathrm{kg}$ para g e, logo após, calculassem a densidade pela fórmula: $\mathrm{d}=\mathrm{m} / \mathrm{v}$. Os dados obtidos da análise das respostas da turma A e B estão disponibilizados nas figuras 1 e 2, respectivamente. 
Problema 1: Um bloco metálico de $100 \mathrm{~cm} 3$ tem massa de 0,9 kg. Determine a

Figura 2: Resultados da análise das respostas da turma A em relação ao problema 1.

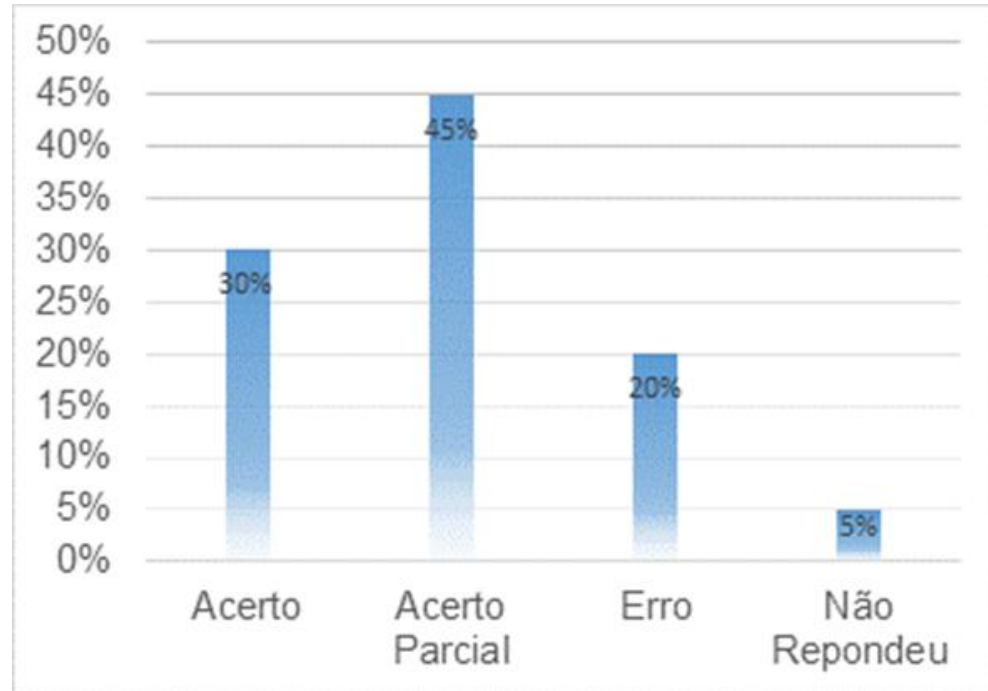

Fonte: Próprios autores (2017).

densidade do metal em g/mL. Dados: $1 \mathrm{~kg}$-------- $1000 \mathrm{~g}$.

Ao comparar as figuras 1 e 2 observa-se o percentual de acertos mais elevado na turma B, porém os acertos parciais foram menores e, além disso, os de erros foram bem maiores em relação os da turma A. Esses resultados podem ser justificados pela análise qualitativa das respostas, onde verificou-se a interpretação da questão realizado pelos alunos da turma A foram mais aceitáveis comparado os da turma B. Os erros ocorridos pelos alunos das turmas A e B estão associados a falta das unidades de medidas, referente ao cálculo da densidade, e

Figura 1: Resultados da análise das respostas da turma B em relação ao problema 1 .

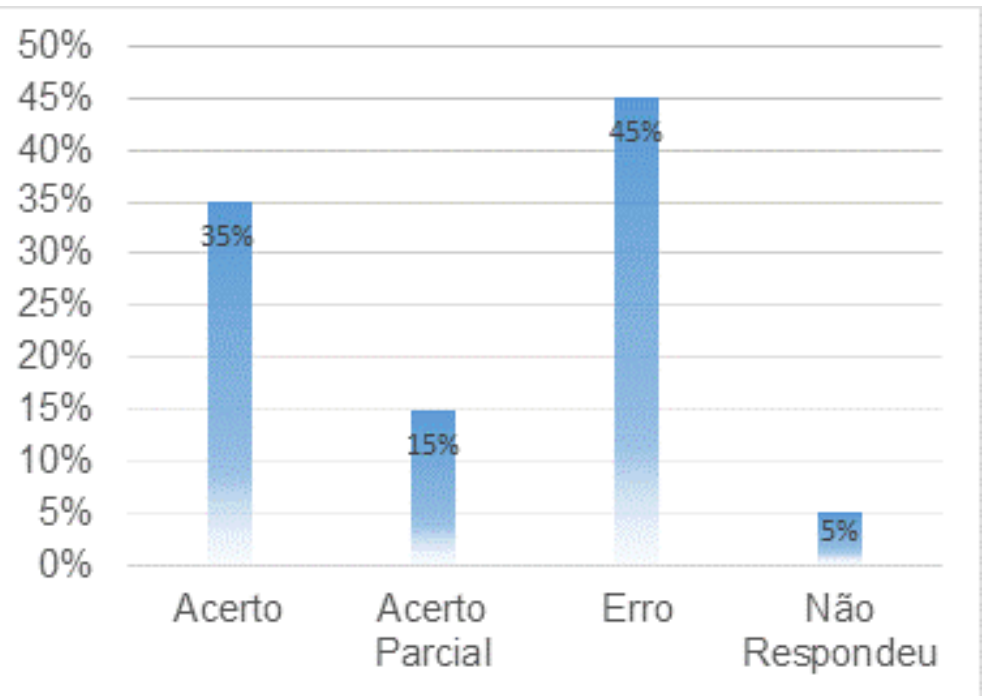


as manipulações das operações matemáticas.

Figura 4: Resultados da análise das respostas da turma A em relação ao problema 2 .

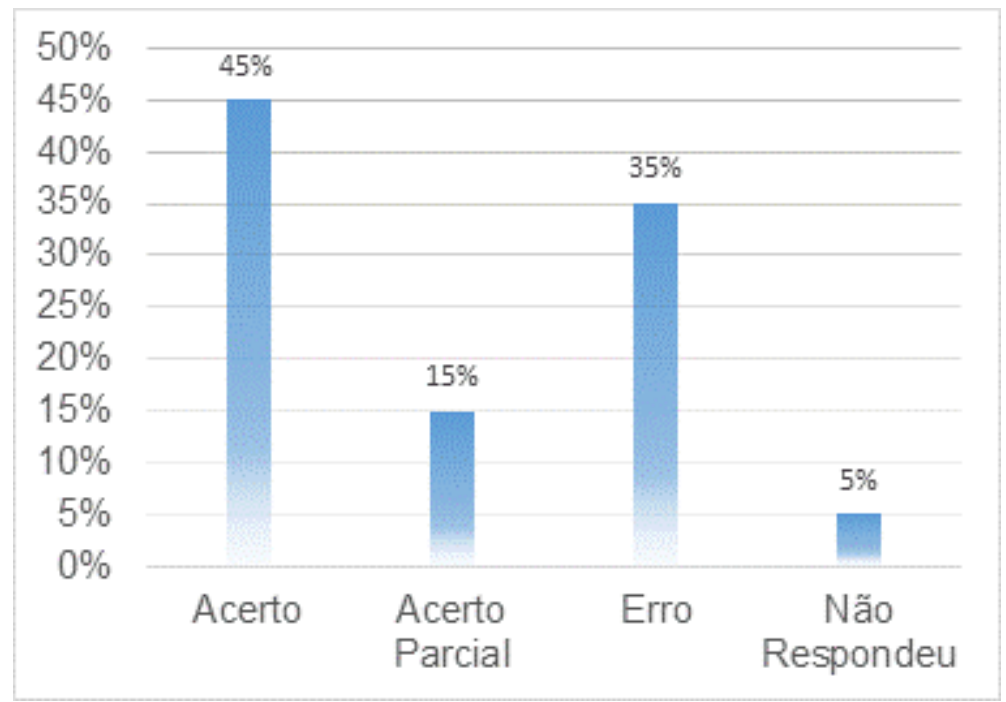

Fonte: Próprios autores (2017).

O problema 02 trazia uma proposta diferenciada do cálculo de densidade, neste foi disponibilizado a massa, em g, e cabia ao aluno descobrir o volume do metal a partir do volume inicial de água, existente na proveta, e do volume final, após a adição da amostra do metal à mesma, a diferença dos volumes, final e inicial, fornecia o volume da amostra, sendo que, logo após a descoberta deste dado podia-se calcular a densidade do metal através da mesma fórmula do problema 1.

Figura 3: Resultados da análise das respostas da turma B em relação ao problema 2 .

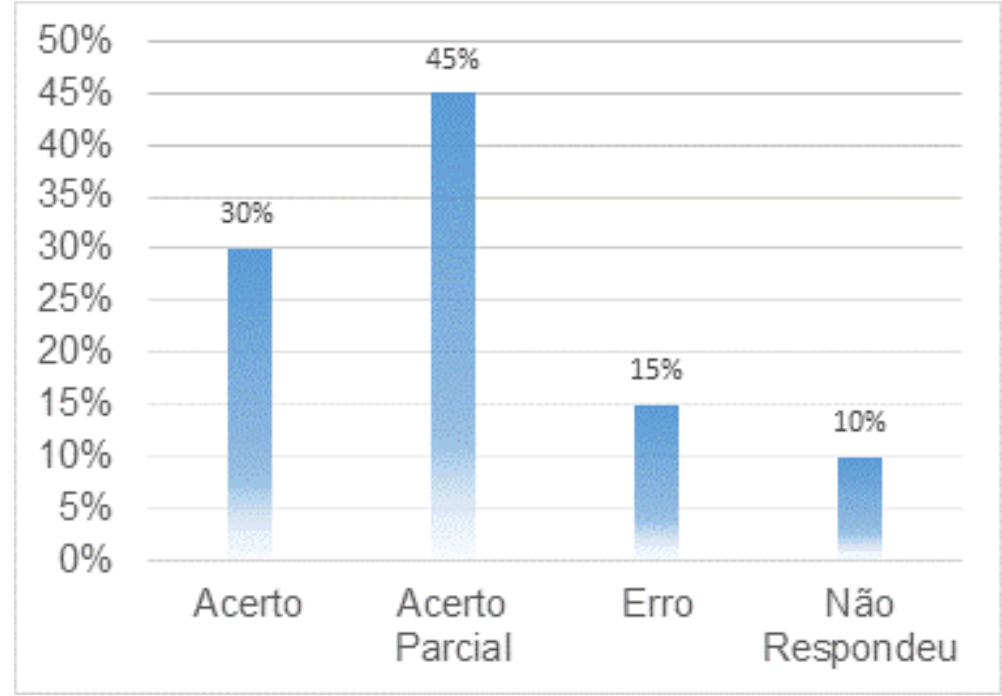

Fonte: Próprios autores (2017). 


\section{PROPEX}

Problema 2: Uma amostra de 72,5 g de um metal desconhecido é colocada em uma proveta que contém $10 \mathrm{~mL}$ de água, provocando um deslocamento no nível da água de forma que o volume final passa a ser de $35 \mathrm{~mL}$. Determine a densidade, em $\mathrm{g} / \mathrm{cm} 3$ do metal desconhecido.

Percebe-se que neste problema os alunos da turma A obtiveram percentual de acertos mais elevado, figuras 3 e 4, mas ouve um decréscimo do número de acertos parciais. Esses resultados demonstram a eficácia do simulador da densidade disponibilizado pelo projeto PhET, onde neste demostra como pode-se calcular o volume de materiais sólidos. $\mathrm{O}$ percentual de acertos parciais elevados na turma B deve-se ao fato deles terem conseguido compreender o cálculo da densidade, mas não entenderam que deveriam encontrar o volume da peça metálica.

O terceiro quesito consistia em descobrir a solubilidade de um sal, a partir dos dados de um certo volume de uma solução saturada, que, após a evaporação do solvente, havia restado apenas uma certa quantidade de sal no recipiente. Com base nessas informações podia-se calcular a solubilidade do sal em um volume de $100 \mathrm{~mL}$ de solvente por uma regra de três simples.

Quesito 3: A tabela a seguir mostra a solubilidade de vários sais à temperatura ambiente. Considere que $50 \mathrm{~mL}$ de uma solução saturada de um desses saís foram completamente evaporados. Se o resíduo obtido em um dos recipientes foi 32g, esse sólido deve ser quais dos apresentados na tabela abaixo?

Figura 5: Resultados da análise das respostas da turma A em relação ao quesito 3 .

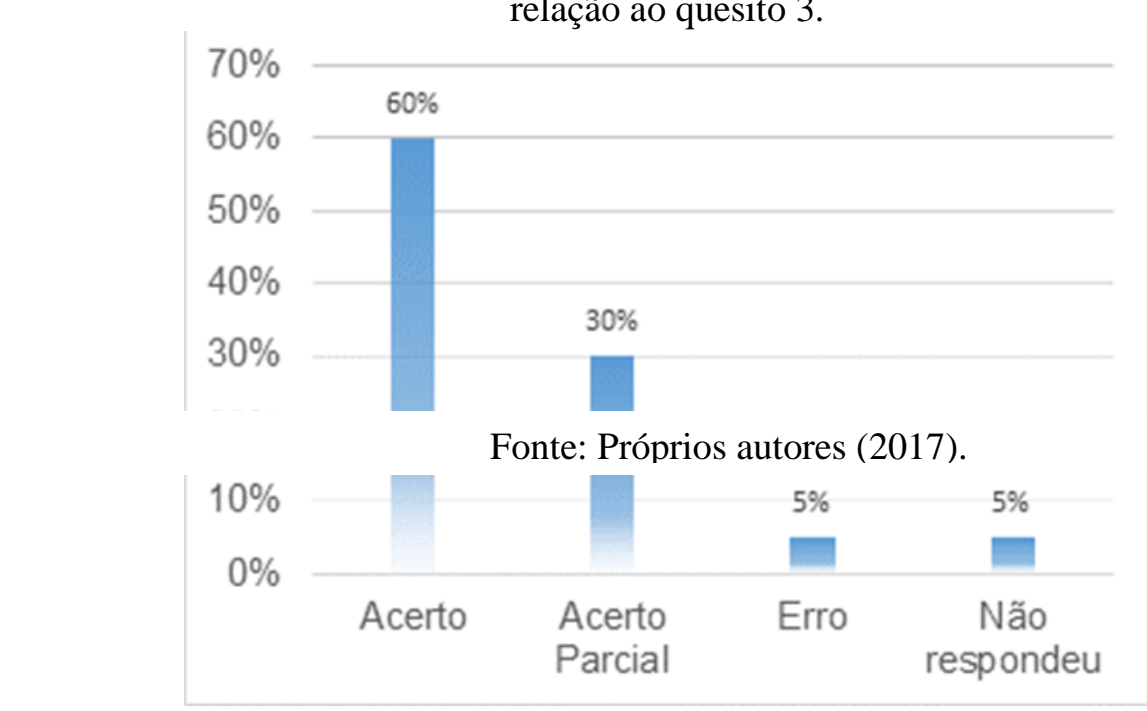

Quadro

Fonte: Próprios autores (2017).

1: Solubilidade 
de alguns sais para resolução do quesito 3 .

\begin{tabular}{|l|c|}
\hline \multicolumn{1}{|c|}{ Sal } & Solubilidade em $\mathbf{g} / \mathbf{1 0 0} \mathbf{~ m L}$ de água \\
\hline Nitrato de prata & 260 \\
\hline Sulfato de alumínio & 160 \\
\hline Nitrato de potássio & 52 \\
\hline Brometo de potássio & 64 \\
\hline Cloreto de sódio & 36 \\
\hline
\end{tabular}

Ao ser comparado os dados das respostas, figuras 5 e 6 , percebe-se que a turma B sobressaiu-se a turma A. Assim, perante o problema 3, tornou-se indiferente a utilização dos objetos virtuais de aprendizagem do ponto de vista quantitativo, porém, do qualitativo observou-se a existência de maior interatividade dos alunos da turma A e maior compreensão dos conceitos no momento da ocorrência das aulas.

Figura 6: Resultados da análise das respostas da turma B em relação ao problema 3 .

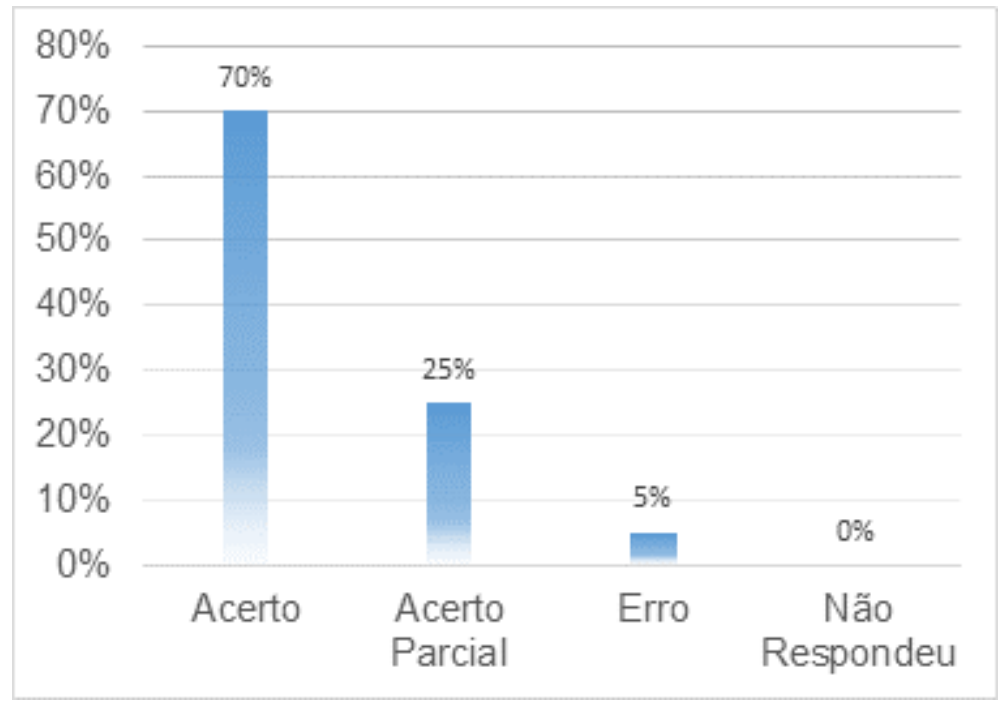

Fonte: Próprios autores (2017). 
No quarto e último problema foi cobrado apenas a compreensão do fenômeno da solubilidade, ou seja, reconhecer certos materiais solúveis em determinados solventes. Neste considerava-se a existência de uma amostra de cloreto de sódio (sal de cozinha), onde uma parte era adicionada a água e outra era aquecida até tornar-se líquida. Cabia aos alunos diferenciar os dois sistemas, sendo assim, uma das respostas possíveis seria informar que um dos sistemas consiste em uma mistura e o no outro uma amostra liquida fundida pode ser solidificada novamente apenas resfriando.

Figura 8: Resultados da análise das respostas da turma A em relação ao problema 4 .

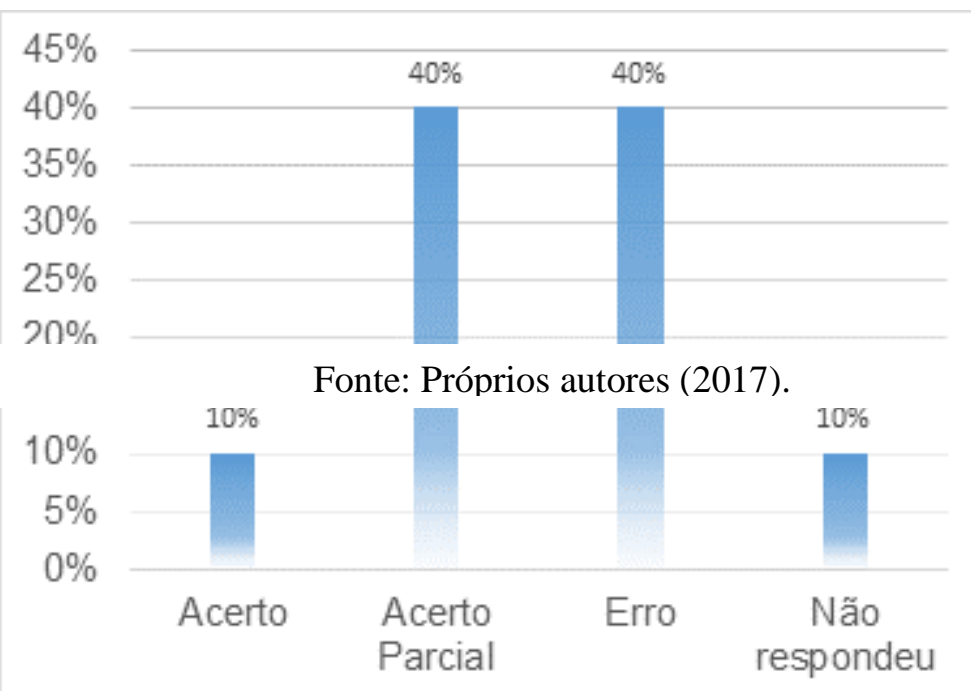

Problema 4: Suponha que você tenha uma amostra de sal de cozinha solido $(\mathrm{NaCl})$. Uma parte de sua amostra será submetida à fusão (processo em que um sólido é aquecido até tornar-se líquido) e outra parte dissolvida em água. Ao final você obterá dois sistemas líquidos. Que diferenças existem entre os dois sistemas resultantes da fusão e da solubilização do sal de cozinha?

Figura 7: Resultados da análise das respostas da turma B em relação ao problema 4.

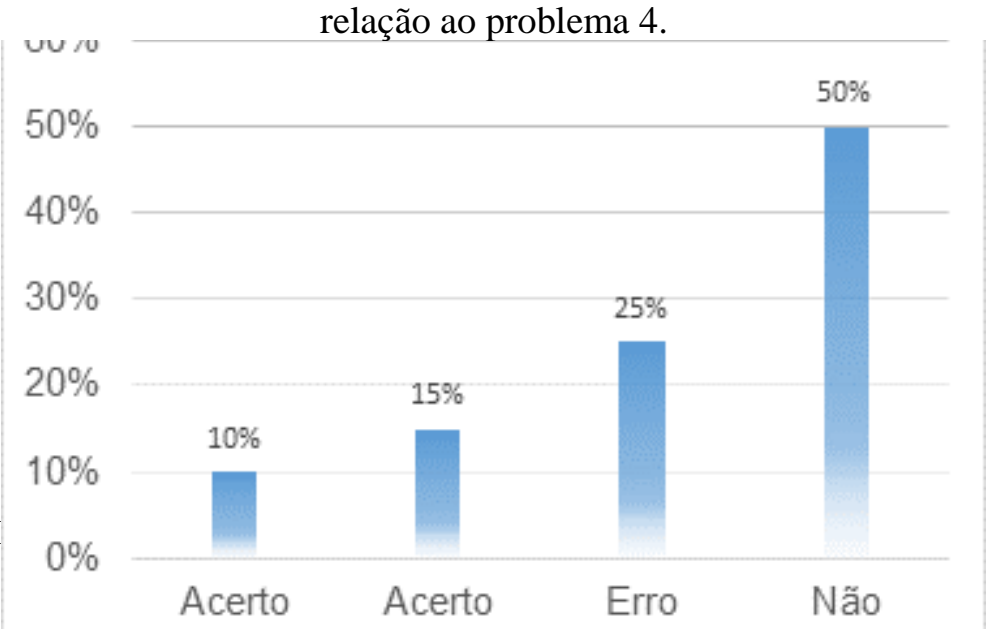




\section{PROPEX}

As figuras 7 e 8 apresentam o resultado obtido no problema 4, percebendo-se que na turma B, 50\% dos alunos, não responderam o item, já que tiveram dificuldades em compreender o problema em questão. Comparando-se o nível de acertos em ambas as turmas, se nota o mesmo resultado, $10 \%$. A diferença mais notável está no número de acertos parciais, onde, na ocasião, a turma A obteve maior desempenho, refletindo o resultado da utilização dos OVA.

No desempenho geral a turma A obteve um melhor resultado, cerca de 5\% a mais da turma B. Isso mostra a eficácia dos OVA, porém, este resultado pode ser melhorado, já que a diferença foi muito pequena quando se comparam as duas turmas, figura 9.

Figura 9: Desempenho médio das turmas

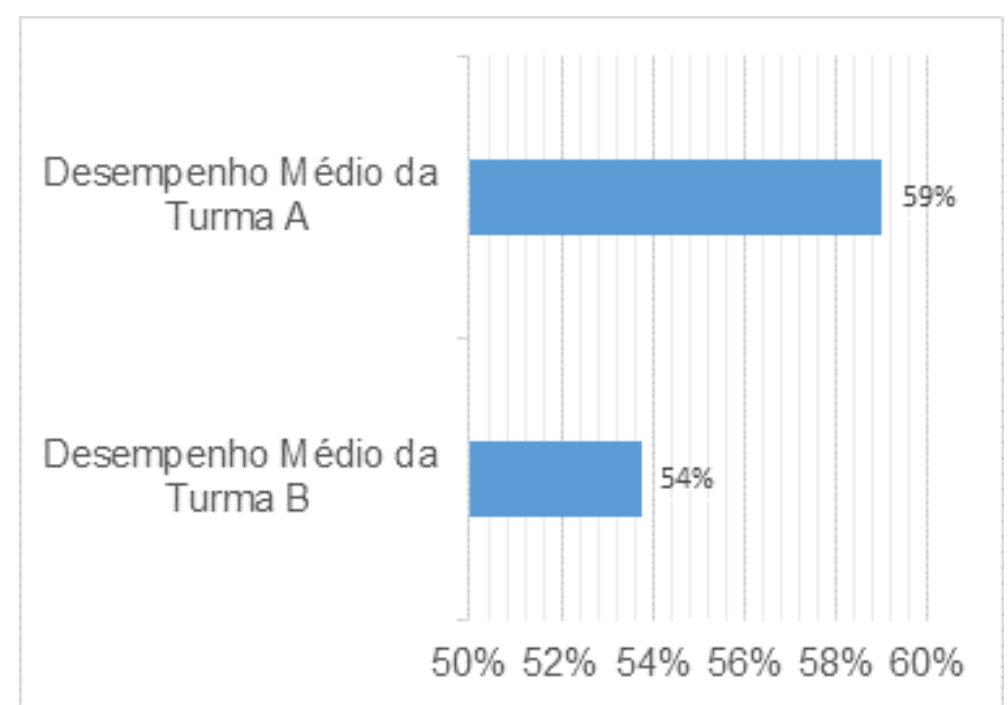

Fonte: Próprios autores (2017).

\section{CONSIDERAÇÕES FINAIS}

No aspecto qualitativo as observações comportamentais dos alunos das turmas A foram excelentes, pois destaca-se uma maior participação, dedicação e compreensão dos fenômenos no momento da aula. Mas o que levou a um resultado quantitativo não muito elevado? A resposta a esta pergunta pode ser diversa, desde o tempo de dedicação dos alunos ao estudo, até a falta de conhecimentos matemáticos, como pode-se observar nas respostas.

O contato com os OVAs proporcionou a contextualização do conhecimento, e assim tornou este mais concreto e sólido. Também estimulou o raciocínio e a exploração de fenômenos, os quais muitas vezes não podem ser explorados na visível, mesmo com o auxílio 
de microscópios. Dessa forma estimular a utilização dos objetos virtuais de aprendizagem pode tornar o ensino mais atraente, estimulando os alunos a buscar o conhecimento e, por consequência, contribuindo com o avanço da química, pois espera-se um maior número de estudantes empenhados nessa área.

Pode-se perceber que a maior dificuldade encontrada pelos alunos durante o desenvolvimento do projeto está na utilização da matemática, pois estes não dominam bem as operações básicas (adição, subtração, multiplicação e divisão). Além disso, não conseguem compreender a importância das unidades de medidas nas ciências.

\section{REFERÊNCIAS BIBLIOGRÁFICAS}

BARÃO, Gladis Constancia. Ensino de Química em ambientes virtuais. In: PARANÁ. Secretaria de Estado da Educação. Superintendência de Educação. O professor PDE e os desafios da escola pública paranaense, 2007. Curitiba: SEED/PR., 2011. v.1. (Cadernos PDE). Disponível em:

<http://www.gestaoescolar.diaadia.pr.gov.br/modules/conteudo/conteudo.php?conteudo=20> Acesso em 12 jan. 2017.

BULEGON, Ana Marli; MUSSOI, Eunice Maria. Pressupostos Pedagógicos de Objetos de Aprendizagem. In: TAROUCO, Liane Margarida Rockenbach. Objetos de Aprendizagem: teoria e prática. Porto Alegre: Evangraf, 2014. 504p.

GALAFASSI, Fabiane Penteado; GLUZ, João Carlos; GALAFASSI, Cristiano. Análise crítica das pesquisas recentes sobre as tecnologias de objetos de aprendizagem e ambientes virtuais de aprendizagem. Revista Brasileira de Informática na Educação, v. 21, n. 3, p. 41-52, 2013.

LAZZARIS, M. J. et al. O uso de simulações computacionais como ferramenta para o ensino da eletroquímica. In: XVII ENCONTRO NACIONAL DE ENSINO DE QUÍMICA, 2014, Ouro preto. Ensino e Aprendizagem. Minas Gerais: [s.n.], 2014. Disponível em:<http://anaiseneq2014.ufop.br/pdf/O\%20USO\%20DE\%20SIMULA\%C3\%87\%C3\%95ES $\% 20$ COMPUTACIONAIS $\% 20$ COMO $\% 20$ FERRAMENTA $\% 20$ PARA $\% 200 \% 20$ ENSINO $\%$ 20DA\%20ELETROQU\%C3\%8DMICA.\%20PN262.pdf> Acesso em: 15 jan. 2017.

LEITE, Werlayne Stuart Soares; RIBEIRO, Carlos Augusto do Nascimento. A inclusão das TIC's na educação brasileira: problemas e desafios. Magis: Revista Internacional de Investigación en Educación, v. 5, n. 10, p. 173-187, 2012. Disponível em: $<$ https://dialnet.unirioja.es/servlet/articulo?codigo=4434902> Acesso em: 23 nov. 2016.

MENEZES, Lilian; BRAGA, Juliana. Estratégias Pedagógicas Para o Uso dos Objetos de Aprendizagem. In: BRAGA, Juliana (org.). Objetos de Aprendizagem: Introdução e fundamentos. Santo André: Editora da UFABC, 2014. 148 p. 
SANTOS, W. L. P. dos; PORTO, P. A. A pesquisa em ensino de química como área estratégica para o desenvolvimento da química. Química Nova. v. 36, n. 10, p. 1570 - 1576, 2013.

SCHWARZELMÜLLER, Anna F.; ORNELLAS, Bárbara. Os objetos digitais e suas utilizações no processo de ensino-aprendizagem. In: Primeira Conferencia Latinoamericana de Objetos de Aprendizaje. 2006. Disponível em: <http://www.bvs.hn/cu2007/ponencias/EDU/EDU022.pdf > Acesso em: 28 nov. 2016.

SOARES, Alessandro Cury; SILVEIRA, Luis Felipe; NUNES, Paula. SIMULAÇÕES VIRTUAIS EM QUÍMICA. Educação, Ciência e Cultura, v. 18, n. 2, p. 131-148, jul - dez 2013. Disponível em:

<http://www.revistas.unilasalle.edu.br/index.php/Educacao/article/viewFile/955/1025> Acesso em: 23 nov. 2016.

SPINELLI, W. Os objetos virtuais de aprendizagem: ação, criação e conhecimento.2007. Disponível em: 〈http://www.lapef.fe.usp.br/rived/textoscomplementares/textoImodulo5.pdf>. Acesso em:11 jan. 2016. 